\title{
Typing and Susceptibility to Penicillin of Neisseria meningitidis Isolated from Patients in Cuba (1993-1999)
}

\author{
Jorge Sosa ${ }^{+}$, Rafael Llanes, Daymi Guzmán, Ibrahín Quintana, Mayra Flores, \\ Oderay Gutiérrez
}

\author{
Instituto de Medicina Tropical "Pedro Kourí”, Autopista Novia del Mediodía km 6, Apdo 601, Marianao 13, \\ Ciudad de La Habana, Cuba
}

The susceptibility to penicillin of 111 Neisseria meningitidis strains was assessed by the agar-dilution procedure and serosubtypes were determined by a whole-cell enzyme-linked immunoassay using monoclonal antibodies reagents. Thirty-five isolates showed reduced sensitivity to penicillin (MIC $\geq 0.1$ $\mathrm{mg} / \mathrm{l}$ and $\leq 1 \mathrm{mg} / \mathrm{l})$ and no resistant strains were detected. The most common phenotype was B:4:P1.15 $(77.5 \%)$ and a rising trend of non-typeable and non-subtypeable strains was detected. The increase in levels of minimal inhibitory concentrations of meningococci to penicillin gives cause for concern and the increase in non-typeable and non-subtypeable isolation demand the use of molecular biology techniques for their typing.

Key words: Neisseria meningitidis - typing - reduced sensitivity - Cuba

Infections due to Neisseria meningitidis (meningococcus) remain a serious health problem. Over 350,000 cases occur worldwide each year, and meningococcal disease (MD) must be notified to the health authorities in many countries (Raymond et al. 1997). The peak of incidence in the epidemic of MD in Cuba, due to N. meningitidis group B, occurred in 1983 when 14.4 cases per 100,000 inhabitants were reported (Valcácel et al. 1991). Investigations to develop an effective anti-meningococcal serogroup B vaccine, composed of different outer membrane proteins, started around 1982 (Almeyda \& Rico 1994). Until the end of 1988 the Cuban anti-meningococcal $\mathrm{BC}$ vaccine (VAMENGOC BC) was firstly administered to highrisk age groups and subsequently to all members of the population between 3 months to 24 years of age. The number of cases subsequently decreased to less than 1.4 per 100,000 inhabitants since 1992 to nowadays (Almeyda \& Rico 1994). It has been demonstrated that the Cuban strains consist almost exclusively of phenotype B:4:P1.15 but strains less susceptible to penicillin have been reported (Martínez et al. 1994, 1997). Even though there

\footnotetext{
${ }^{+}$Corresponding author. Fax: $+537-24.6051$. E-mail: sosa@ipk.sld.cu

Received 25 April 2000

Accepted 21 March 2001
}

exists a low incidence of MD in our environment, it is still necessary to keep a surveillance of serogroup, serotype and subtype, and antimicrobial susceptibility of $N$. meningitidis strains. In this study we determined the serogroup, serotypes and subtypes distribution, and measured the susceptibility to penicillin of a group of $N$. meningitidis strains isolated from 1993 to 1999.

One hundred and eleven isolates of $N$. meningitidis recovered from blood and cerebrospinal fluid (CSF) of patients with systemic MD were randomly selected and studied. All strains were from sporadic cases and small outbreak that occurred in the 14 provinces of Cuba from 1993 to 1999. The strains were received at the National Reference Laboratory for Pathogenic Neisseria (NRLPN) and were grown on Müeller-Hinton agar (Oxoid, Hamshire, England) containing 7\% calf serum (LABIOFAM) with incubation at $37^{\circ} \mathrm{C}$ in $\mathrm{CO}_{2}$ atmosphere overnight. For identification of $N$. meningitidis Gram staining, oxidase, catalase, carbohydrate degradation test and production of $\gamma$-glutamiltransferase enzyme (Diagnostics Pasteur) were used. Finally the strains were stored at $-70^{\circ} \mathrm{C}$ as suspension in $20 \%$ glycerol ( $\mathrm{vol} / \mathrm{vol})$, in Brain Heart Infusion (Oxoid) until further processing. Antimicrobial susceptibility test on Müeller Hinton agar medium supplemented with sheep blood (5\% $\mathrm{v} / \mathrm{v})$ was performed as previously described (NCCLS 2000, M7A5). The conventional penicillin MIC of $\geq 0.1 \mathrm{mg} / \mathrm{l}$ to $1 \mathrm{mg} / \mathrm{l}$ was used to denote strains with reduced susceptibility (Hughes et al. 
1993). Serogroups were determined by slide agglutination with polyclonal antisera to serogroups A,B,C,W135,X,Y and Z (Wellcome Diagnostics). Serotype and subtype were determined by a wholecell ELISA using the monoclonal antibody reagents (Abdillahi \& Poolman 1987).

The susceptibility to penicillin of 111 meningococcal strains was assessed by the agar-dilution procedure. Thirty-five $(31.5 \%)$ isolates showed reduced sensitivity to penicillin and no resistant strains $(\geq 2 \mathrm{mg} / \mathrm{l})$ were detected. The 111 isolates belonged to group B and the most common association of serogroup, serotype and subtype was B:4:P1.15 (86/77.5\%). This phenotype was also predominant for both categories of susceptibility. The remaining 25 (22.5\%) strains exhibited different serotype and subtype combinations (Table). It is important to note that the proportion of isolates with phenotypes other than B:4:P1.15 in the group of strains with reduced sensitivity to penicillin $(28.6 \%)$ was greater than in the sensitive group (19.7\%).

Although penicillin resistant strains have never been detected in Cuba until now, strains with reduced sensitivity to this drug have been increasing in our environment. Accumulated data on susceptibility to penicillin exists in our laboratory dating from 1986, and in that year already $24 \%$ of meningococcal strains showed reduced sensitivity to this drug (Martínez et al. 1997). During the first years the MIC of strains received in our laboratory did not exceed $0.15 \mathrm{mg} / \mathrm{l}$ (unpublished observations). The isolates with reduced sensitivity to penicillin

\section{TABLE}

Distribution of serogroup, serotype and subtype of 111 strains according to susceptibility categories for penicillin

\begin{tabular}{lccc}
\hline $\begin{array}{l}\text { Serogroup, } \\
\text { serotype and } \\
\text { subtype }\end{array}$ & $\begin{array}{c}\text { Susceptible } \\
\text { (no./\%) }\end{array}$ & $\begin{array}{c}\text { Reduced } \\
\text { sensitivity } \\
\text { (no./\%) }\end{array}$ & $\begin{array}{c}\text { Total } \\
\text { (no./\%) }\end{array}$ \\
\hline B4:P1.15 & $61(55)$ & $25(22.5)$ & $86(77.5)$ \\
B4:NST & $3(2.7)$ & $3(2.7)$ & $6(5.4)$ \\
B4:P1.12,15 & $4(3.6)$ & 0 & $4(3.6)$ \\
B4:P1.2,5 & $2(1.8)$ & $2(1.8)$ & $4(3.6)$ \\
NT:P1.NST & $1(0.9)$ & $2(1.8)$ & $3(2.7)$ \\
B15:P1.15 & $1(0.9)$ & $1(0.9)$ & $2(1.8)$ \\
B15:P1.NST & 0 & $1(0.9)$ & $1(0.9)$ \\
B4:P1.4 & $1(0.9)$ & 0 & $1(0.9)$ \\
B15:P1.16 & 0 & $1(0.9)$ & $1(0.9)$ \\
BNT:P1.5,13 & $1(0.9)$ & 0 & $1(0.9)$ \\
B15:P1.13 & $1(0.9)$ & 0 & $1(0.9)$ \\
NT:P1.NST & $1(0.9)$ & 0 & $1(0.9)$ \\
\hline Total & $76(68.5)$ & $35(31.5)$ & $111(100)$ \\
\hline
\end{tabular}

in the present study exhibited values between 0.125 and $1 \mathrm{mg} / \mathrm{l}$ with the $\mathrm{MIC}_{50}$ and $\mathrm{MIC}_{90}$ of $0.25 \mathrm{mg} /$ 1 and $0.5 \mathrm{mg} / \mathrm{l}$ respectively. In the Netherlands, 1,125 meningococcal strains isolated from blood or CSF were studied and the prevalence of intermediate penicillin-resistance meningococci was 3.3\% (Enting et al. 1996). Sáez Nieto et al. (1997) described an increase of meningococcal strains showing MICs between 0.12 and $1 \mathrm{mg} / \mathrm{l}$ from $0.4 \%$ in 1985 and reaching $42.6 \%$ in 1990 . Such isolates have been reported elsewhere in Europe, in South Africa, and in Canada (Woods et al. 1994). Six meningococci, isolated from patients and carriers during a large epidemic of meningococcal meningitis in Malawi had MICs of penicillin ( $>$ or $=2$ $\mathrm{mg} / \mathrm{l}$ ) high enough to render them clinically resistant (Bellete et al. 1994). According to our outcome we do not exclude the possibility that strains with MICs higher than $1 \mathrm{mg} / \mathrm{l}$ may appear in the future. Thus the emergence of penicillin resistance among strains of $N$. meningitidis would require a reconsideration of current clinical practice with regard to treatment of meningococcal disease.

In Spain (Barcelona) overall 498 strains of $N$. meningitidis, obtained between the years 1986 and 1997, from children with sepsis and/or meningitis, 403 strains belonged to serogroups B and 77 to serogroup C; penicillin-intermediate resistance rates ranged from $9.1 \%$ in 1986 to $71.4 \%$ in 1997 and it was more common among strains belonging to serogroup C (52\% of resistant strains) than to serogroup B (22.1\% of resistant strains). The most prevalent phenotype between 1990 and 1996 was B:4:P1.15 (Latorre et al. 2000). In our study, between 1993 and 1999 we found a $77.5 \%$ of B4:P1.15 isolates. Non-typeable and nonsubtypeable strains were observed in $4.5 \%$ and 9\% respectively. This results argues strongly for the establishment of an epidemiological monitoring system of susceptibility to penicillin and will demand the use of molecular biology techniques for characterization of $N$. meningitidis circulating in Cuba. The present study updates the susceptibility data on penicillin and, serogroup and sero/ subtypes distribution - through monoclonal antibody analysis - of menigococci in Cuba. Genotyping methods have not been consistently used to identify meningococcal isolates in Cuba; we believe other methods, like pulsed field and multilocus enzyme electrophoresis, will be useful to support more complete studies.

\section{ACNOWLEDGMENTS}

To Dr Muhamed-Kheir Taha, for his contribution submitting control strains for performance of whole-cell enzyme-linked immunoassay with the monoclonal antibody reagents used in the present work. 


\section{REFERENCES}

Abdillahi H, Poolman JT 1987. Whole-cell ELISA for typing Neisseria meningitidis with monoclonal antibodies. FEMS Microbiol Lett 48: 367-371.

Almeyda L, Rico O 1994. Información general sobre la enfermedad meningocóccica en Cuba. Vacuna para su prevención y alcance. Rev Hosp Niños B Aires $X X X V I(159 / 159)$ : 234-241.

Bellete B, Cuevas LE, Kazembe P, Mughogho G, Sunderland D, Hart CA 1994. Meningococcal disease in Malawi: studies on the genetic relatedness of the bacteria. Ann Trop Med Parasitol 88: 59-64.

Enting RH, Spanjaard L, van-de-Beek D, Hensen EF, de-Gans J, Dankert J 1996. Antimicrobial susceptibility of Haemophilus influenzae, Neisseria meningitidis and Streptococcus pneumoniae isolates causing meningitis in The Netherlands, 1993-1994. J Antimicrob Chemothe 38: 777-786.

Hughes JH, Biedenbach DJ, ErwinME, Jones RN 1993. E test as susceptibility test and epidemiologic tool for evaluation of Neisseria meningitidis isolates. $J$ Clin Microbiol 31: 3255-3259.

Latorre C, Gene A, Juncosa T, Munoz C, Gonzalez-
Cuevas 2000. Neisseria meningitidis: evolution of penicillin resistance and phenotype in a children's hospital in Barcelona, Spain. Acta Paediatr 89: 661665.

Martínez I, Palma S, Alonso R, Valdés E, Llanes R, Sosa J, Bravo J 1997. Detección de cepas de $N$. meningitidis con susceptibilidad intermedia a la penicilina. Enf Infec Microb 17: 23-26.

NCCLS-National Committee for Clinical Laboratory Standards 2000. Methods for Dilution Antimicrobial. Susceptibility Test for Bacteria that Grow Aerobically. Document M7A5 (M100-S10).

Raymond NJ, Reeves M, Allejo G, Baughman W, Gheesling LL, Carlone GM, Wenger JD, Stephens DS 1997. Molecular epidemiology of sporadic (endemic) serogroup $\mathrm{C}$ meningococcal disease. J Infect Dis 176: 1277-1284.

Valcárcel NM, Rodríguez C, Terry H 1991. La Enfermedad Meningocócica en Cuba. Cronología de una Epidemia, Ciencias Médicas, Ciudad de la Habana, Cuba.

Woods CR, Smith AL, Wasilauskas BL, Campos J, Givner LB 1994. Invasive disease caused by Neisseria meningitidis relatively resistant to penicillin in North Carolina. J Infect Dis 170: 453-456. 
526

Typing and Susceptibility to Penicillin of N. meningitidis • Jorge Sosa et al. 